\title{
TFAP2E and MLH1 Genes Methylation Pattern and Microsatellite Instability as Predictors of Rectal Cancer Response to Neoadjuvant Chemoradiotherapy
}

\author{
Mohammed M. Rizk ${ }^{1}$, Alaa E. Kandil ${ }^{2}$, Suzan M. Helal ${ }^{3}$, Waleed G. Elshazly \\ ${ }^{4}$, Doreen N. Younan ${ }^{1}$, Eman Z. Elkemary ${ }^{1}$
}

${ }^{1}$ Clinical and Chemical Pathology Department, Faculty of Medicine, Alexandria University, Alexandria, Egypt; ${ }^{2}$ Clinical Oncology and Nuclear Medicine Department, Faculty of Medicine, Alexandria University, Alexandria, Egypt; ${ }^{3}$ Pathology Department, Faculty of Medicine, Alexandria University, Alexandria, Egypt; ${ }^{4}$ Surgery Department, Faculty of Medicine, Alexandria University, Alexandria, Egypt

\begin{abstract}
Background: Neoadjuvant chemoradiotherapy (nCRT) prior to surgery in rectal cancer has several adverse effects. Predictive biomarkers for response to nCRT are needed to save patients unnecessary toxicities and to take a timely tailored treatment decision. Epigenetic modifications like DNA methylation patterns have been suspected to be potential predictive biomarkers.

Aim: To determine the role of TFAP2E and MLH1 genes' methylation status and microsatellite instability (MSI) in predicting response to 5-fluorouracil - based nCRT in rectal cancer.

Methods: DNA was extracted from 80 patients with newly diagnosed stage II / III rectal cancer. The methylation status of TFAP2E and MLH1 genes was determined by pyrosequencing and MSI was determined using 5 microsatellite loci by conventional polymerase chain reaction and capillary electrophoresis.

Results: The cut-off values for TFAP2E \& MLH1 genes 'methylation level were 40\% and 15\% by receiver operating characteristic curve analysis. Hypermethylated TFAP2E and MLH1 gene promotors and MSI were predominant among non-responders ( $\mathrm{p}<0.001,<0.001$ and $=0.022$; respectively). Other factors associated with significantly higher pathological response to nCRT were well/moderately differentiated adenocarcinoma, pretreatment carcinoembryonic antigen level $\leq 5 \mathrm{ng} / \mathrm{ml}$ and rectal tumor $\leq 5 \mathrm{~cm}$ from the anal verge.

Conclusion: Hypermethylated TFAP2E and MLH1 gene promotors and MSI in rectal cancer tissue were associated with poor response to 5-fluorouracil - based nCRT. They might be of value in predicting the response of rectal cancer to nCRT and in tailoring its treatment.
\end{abstract}

Keywords: Epigenetics, MLH1 gene, Microsatellite instability, Neoadjuvant chemoradiotherapy, Rectal cancer, TFAP2E gene

Corresponding Author: Dr. Doreen N. Younan; Clinical Pathology Department, Faculty of Medicine, Alexandria University, Khartoom Square, Azarita, Alexandria, Egypt; E-mail: doreenyounan@hotmail.com

Submitted: 16-July-2020, Revised: 17-September-2020, Accepted: 8-October-2020, Published online: 9-November-2020

\section{Introduction}

Colorectal cancer (CRC) is a disease with a major worldwide burden. It is the third most common cancer diagnosed in both males and females. It has heterogeneous clinical presentations, prognosis and individual treatment response ${ }^{1}$.

Rectal cancer has a striking complication, which is the high recurrence rate; $4-33 \%{ }^{2}$. Aiming at reducing the recurrence rate and downstaging the tumor prior to surgery, neoadjuvant chemoradiotherapy (nCRT) is recommended for a group of rectal cancer patients by the National Comprehensive Cancer Network (NCCN) and others 3,4 .

The major benefits of pre-operative nCRT are to reduce tumor mass, decrease the thickness of invasion of tumor into the intestinal wall and 
achieve clinical down-staging of tumor ${ }^{5}$. However, its outcome varies from a favorable 'pathological complete response', which occurs in $10-20 \%$ of patients, to 'no benefit from treatment' and delayed opportunity of surgery with tumor growth during this period and even the development of distant metastasis ${ }^{6,7}$.

Considering the severe secondary effects of nCRT observed, reliable predictive biomarkers are strongly needed to predict the response of patients to the treatment and to identify non-responders and thus avoiding costly, long, and ineffective therapy with its adverse effects and getting benefit from other personalized treatment ${ }^{8}$.

The recent introduction of epigenetic studies revealed characteristic DNA methylation pattern of cytosine guanine islands (CGIs) in rectal cancer. With these advances, a major potential lies in the use of DNA methylation patterns as a reliable and effective diagnostic, prognostic and predictive biomarkers to the response to 5-flurouracil (5-FU)based nCRT in rectal cancer ${ }^{9}$.

One of these predictive biomarkers is the transcription factor activating protein 2 epsilon (TFAP2E) gene which is located on chromosome 1 p34 and has multiple CGIs with the potential for regulation of its expression by means of its CGIs' hypermethylation. It was found that hypermethylation of this gene is associated with its decreased expression, that is associated with clinical non-responsiveness to 5FU-based nCRT. Moreover, induction of TFAP2E expression was triggered by using de-methylating drugs ${ }^{10,11}$.

Another one is the mut L homolog 1 (MLH1) gene, which is located on chromosome $3 p 22.2$. It is a member of a group of genes known as DNA mismatch repair (MMR) genes that are responsible for recognition and repairing of DNA errors that occur during DNA replication ${ }^{12}$.

It was found that MLH1 gene hypermethylation with subsequent silencing of this gene correlates with loss of the MLH1 protein and DNA repairing mechanisms and provokes a characteristic molecular phenotype called microsatellite instability (MSI), displaying a form of genetic instability characterized by the accumulation of numerous mutations within repetitive sequences of DNA in non-encoding microsatellite regions, which has a predictive role in response to nCRT ${ }^{13,14}$.

It was reported that patients with MLH1 gene hypermethylation with MMR-deficient tumors and MSI did not respond to 5-FU-based nCRT, whereas those with MMR-proficient tumors and microsatellite stability (MSS) had a significant response to this treatment ${ }^{15}$. Moreover, it was reported that treatment of rectal cancer by demethylating agents (which de -methylate genes like MLH-1) results in enhanced chemo-radiation sensitivity ${ }^{16}$.

So, epigenetic methylation markers are suspected to be predictive markers to treatment response in rectal cancer. This information could be critical in the choice of chemotherapeutic treatment, especially considering recently developed new inhibitors of DNA methylation ${ }^{17}$.

Insufficient attention has been paid to this important clinical issue. Moreover, to the best of our knowledge, published studies did not separate rectal cancer and studied rectal and colon cancer together ${ }^{18}$.

In this study, we aimed at determining the predictive role of methylation markers (TFAP2E and MLH1 genes) and MSI status in response to nCRT among Egyptian patients with rectal cancer.

\section{Methods}

\section{Patients}

This study was conducted on 80 Egyptian patients with newly diagnosed rectal cancer stages II and III by magnetic resonance imaging (MRI) and biopsy, admitted to the Colorectal Surgery Department at Alexandria Main University Hospital, Alexandria, Egypt. All were scheduled to receive nCRT before surgery.

Full history was taken from all patients including; personal history (name, age, diet habits, smoking, alcohol intake and physical exercise), family history (CRC, gastro-intestinal, breast and genital cancers, age at diagnosis and outcome), past history (of exposure to previous chemotherapy, radiotherapy, X-ray, CT or MRI on colon and colorectal biopsy) and present history (regarding the main complaints as tenesmus, mucorrhae, anal bleeding, discharge, pain, abnormal bowel habits, weight loss and their duration). Digital rectal examination was done to assess the distance of the rectal mass from the anal verge.

\section{Carcinoembryonic antigen (CEA)}

Carcinoembryonic antigen was measured before starting nCRT, using ADVIA Centaur XP (Siemens Healthcare diagnostics, USA) ${ }^{19}$. 


\section{Genomic study of endoscopic samples}

1. Tissue sampling: Eighty endoscopic formalin fixed paraffin embedded (FFPE) rectal cancer tissue specimens were collected from 80 patients before starting nCRT. Five $\mu \mathrm{m}$ thick sections were dissected from each specimen, stained with haematoxylin and eosin (H\&E) to determine locations of tumor tissue and adjacent normal tissue. Eight to ten cut sections, $10 \mu \mathrm{m}$ thick, were dissected from each endoscopic FFPE biopsy from tumor tissue and from the adjacent normal tissue and were put into two separate Eppendorfs.

2. DNA extraction: DNA was extracted from tumor and adjacent normal tissues by QIAamp® DNA FFPE tissue kit for purification of genomic DNA from FFPE tissues according to the manufacturer's instructions (catalog \# 56404, Qiagen, Germany) ${ }^{20}$. The DNA samples were stored at $-20^{\circ} \mathrm{C}$ until use.

3. Assessment of TFAP2E and MLH1 genes' methylation level in rectal tumor tissue samples:

3.1. DNA Bisulphite conversion 21: DNA Methylation-Gold kit (Catalog \# D5005, ZYMO RESEARCH, USA) was used to treat DNA with bisulfite, which converts unmethylated cytosines into uracils and methylated cytosines remain unchanged during the treatment.

3.2. Polymerase chain reaction (PCR) amplification: The Bisulphite converted DNA was amplified according to manufacturer's instructions of Pyro Mark PCR Kit (200 runs, cat \# 978703, Qiagen, Germany). The PCR reaction mix was set up as follows: $12.5 \mu \mathrm{l}$ PyroMark PCR master mix (2x), $2.5 \mu \mathrm{l}$ CoralLoad Concentrate (10x), $2.5 \mu \mathrm{l}$ PCR primers (10x), $5.5 \mu \mathrm{l}$ RNase-free water, $2 \mu \mathrm{l}$ Bisulfite converted DNA, to bring a total volume of $25 \mathrm{ul} /$ reaction. Primers were included in the PyroMark CpG assay kit (cat \# 978746, Qiagen, Germany). One set for MLH1 gene (PM00104832) and the other for TFAP2E gene (PM00001260) amplification (one primer in each set that was biotin 3' labelled). Thermal cycler (SimpliAmp, applied biosystems, Thermo Scientific, USA) was programmed according to the manufacturer's instructions. After amplification, the PCR product was checked prior to pyrosequencing analysis by agarose gel analysis.

3.3. Detection of promotor methylation status of TFAP2E and MLHI genes by Pyrosequencing Technique 22: The detection of promotor methylation level of TFAP2E and MLHI genes in the amplified DNA was done according to manufacturer's instructions of Pyro Mark Gold Q24 reagents kit (24x5 runs, cat \# 971802, Qiagen, Germany) on PyroMark Q24 sequencer as well as PyroMark Q24 software for analysis. Preparation of the reaction mix for pyrosequencing was done by adding $1 \mu \mathrm{l}$ Sepharose beads $(5 \mathrm{ml}$, lot no.10048166, GE Healthcare Bio-science, USA), $40 \mu \mathrm{l}$ binding buffer, $29 \mu \mathrm{l}$ high purity water and $10 \mu \mathrm{l}$ amplified biotinylated DNA sample bringing the total volume to $80 \mu \mathrm{l}$ in each Eppendorf.

Preparation of Pyromark Q24 plates was done by adding $22.5 \mu \mathrm{l}$ of annealing buffer to $2.5 \mu \mathrm{l}$ of sequencing primer which was included in the PyroMark CpG assay kit (cat \# 978746, Qiagen, Germany). One set for TFAP2E gene (PM00001260) and the other for MLH1 gene (PM00104832). The pyrosequencing assays were designed to analyze the following sequences:

- For TFAP2E gene promotor (with 6 Cpg sites) (Figure 1): CTGGCGGCAACGCLGAATCCㅡㄷAGTG ACCGCGGA.

- For MLH1 gene promotor (with $3 \mathrm{CpG}$ sites):

CGTAAGCTACAGCTRAAGGAAGAACGT GAGCACGA.

Methylation percentage of each CpG site was displayed in a pyrogram, and was calculated as the cytosine: thymine ratio, methylated: unmethylated cytosine. Average \% methylation of the whole sequence was calculated as the mean of the six CpG sites' methylation \% in the region of TFAP2E gene and three CpG sites methylation \% in the region of MLH1 gene.

4. Assessment of MSI status in the rectal tumor tissue and the adjacent normal tissue by conventional PCR:

4.1. PCR amplification: The extracted DNA from both tumor tissue and adjacent 
normal tissue from each patient was amplified using lyophilized primers (Invitrogen, Thermo Fisher Scientific, UK) for five loci (BAT-25, BAT-26, D5S346, D17S250 and D2S123), recommended by Bethesda protocol, and Taq Red Mix, master mix with loading dye (cat \# 25044, Bioline, UK). The primer sequences of the five microsatellite loci were as follows:

BAT-25-F:5' CTCGCCTCCAAGAATGTAAGT-3' BAT-25-R:5' CTATGGCTCTAAAATGCTCTGTTC-3' BAT-26-F:5' TGACTACTTTTGACTTCAGCC-3' BAT-26-R:5' AACCATTCAACATTTTTAACCC-3' D5S346-F:5' ACTCACTCTAGTGATAAATCG-3' D5S346-R:5' AGCAGATAAGACAGTATTACTAGTT-3' D17S250-F:5' GGAAGAATCAAATAGACAA-3' D17S250-R:5' GCTGGCCATATATATATTTAAACC-3' D2S123-F: 5'AATGGACAAAAACAGGATGC-3' D2S123-R:5' CCCTTTCTGACTTGGATACC-3'

They were dissolved in high purity water. $1 \mu \mathrm{l}$ of forward primer, $1 \mu \mathrm{l}$ of reverse primer, $12.5 \mu \mathrm{l}$ of master mix, $200 \mathrm{ng}$ of DNA and high purity water were dispensed into each $0.2 \mathrm{ml} \mathrm{PCR}$ tube with a total volume of $25 \mu \mathrm{l}$ for amplification. The thermal cycler (SimpliAmp, applied biosystems, Thermo Scientific, USA) was programmed as follows: initial denaturation $94^{\circ} \mathrm{C}$ for 2 minutes then 35 cycles of three steps; denaturation $94^{\circ} \mathrm{C}$ for $15 \mathrm{sec}$, annealing $56^{\circ} \mathrm{C}\left(52^{\circ} \mathrm{C}\right.$ for D17S250 only) for $30 \mathrm{sec}$, extension $72^{\circ} \mathrm{C}$ for $60 \mathrm{sec}$.
Detection and differentiation of PCR fragments were performed on the QIAxcel Advanced capillary electrophoresis system.

4.2. Detection of MSI status on QIAxcel Advanced Capillary Electrophoresis System ${ }^{23}$ : Tumor and normal amplicons of each locus for each patient were tested side by side in the sample strip and their electropherograms were superimposed on each other to detect the absence or presence of instability in each locus ${ }^{24}$ (Figure2).

4.3. Definition of MSI: Three categories of MSI have been defined by the National Cancer Institute; MSI-high (MSI-H) indicating instability in two or more loci, MSI-low (MSI-L) indicating instability in one locus only and microsatellite stability (MSS) indicating absence of instable loci. ${ }^{24,25} \mathrm{In}$ our study, cases of MSS and MSI-L were considered as MSS, and cases of MSI-H were considered as MSI, as previously grouped by Sargent et al. ${ }^{14}$

\section{Neoadjuvant chemoradiotherapy determination of tumor's response}

Patients were subjected to long-course of nCRT. The radiation dose delivered was 50.4Gy (1.8Gy in 28 daily fractions) with infusional 5-FU $\left(1000 \mathrm{mg} / \mathrm{m}^{2}\right.$ daily for five days during the $1^{\text {st }}$ and $5^{\text {th }}$ weeks of

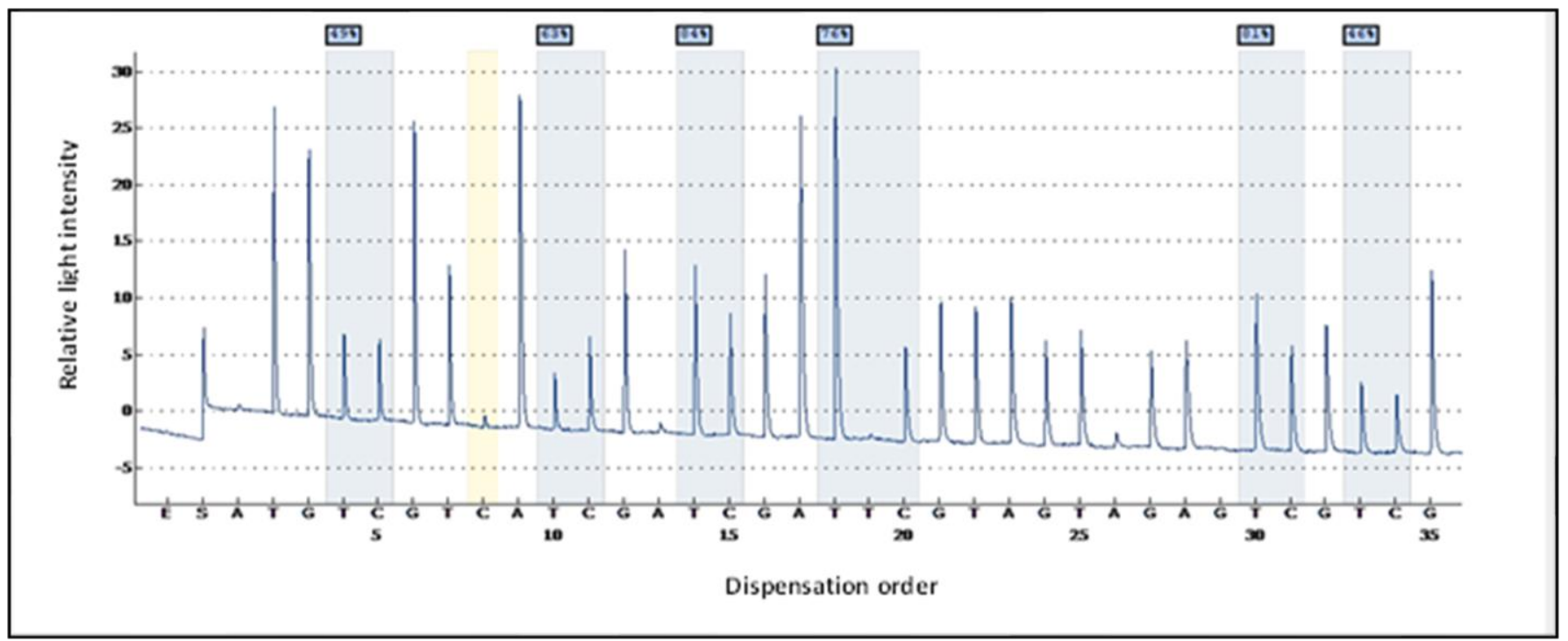

Figure 1: Pyrogram of methylation level of the six CpG sites in the TFAP2E gene promotor (The 6 blue-gray shaded areas of the pyrogram correspond to the $6 \mathrm{CpG}$ sites interrogated in TFAP2E gene promotor; $\mathrm{X}$ axis: Dispensation order, Y-axis: Relative light intensity) 


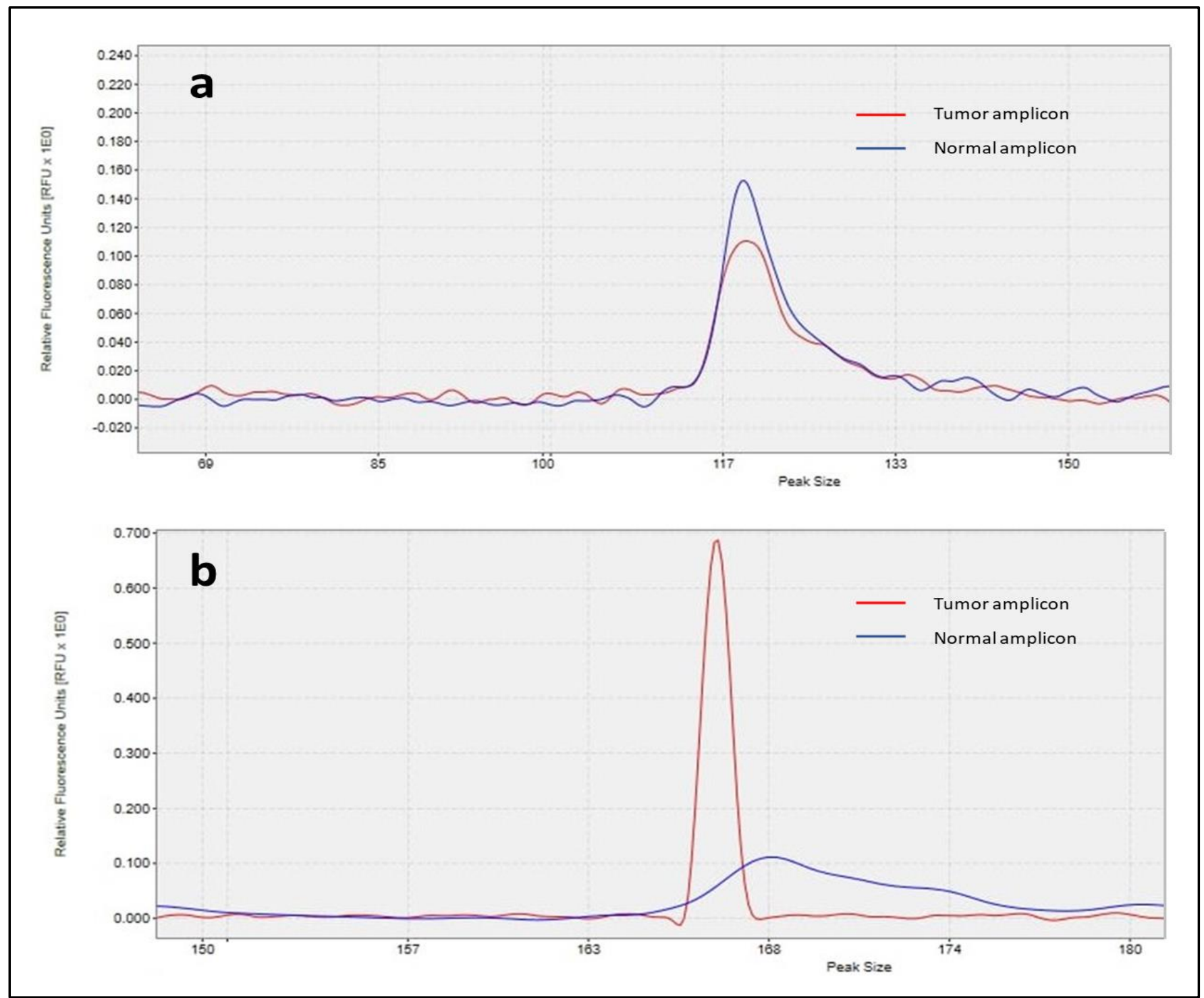

Figure 2: Electropherograms showing a) Stability of BAT-26 locus, b) Instability of D2S123 locus (Tumor and normal amplicons of each locus were superimposed on each other in the electropherogram determining either stability, if they coincide together, as in a) for BAT 26 locus, or instability, if they do not coincide, as in b) for D2S123 locus.; X-axis: Peak size, Y-axis: Relative fluorescence units)

radiotherapy) or oral 5-FU all through the radiotherapy course at the Clinical Oncology Department - Alexandria Main University Hospital. Determination of the tumor's response to nCRT was done by pre and post neoadjuvant MRI according to Response Evaluation Criteria in Solid Tumors (RECIST) criteria ${ }^{26}$ (patients with complete response [CR] or partial response [PR] were classified as responders and patients with progressive disease [PD] or stationary disease [SD] were classified as non-responders), and by postsurgical pathological examination according to Mandard tumor regression grade (TRG) classification 27 (patients were divided into responders [grades 1 to 3 ] and non-responders [grades 4 and 5]).

\section{Statistical analyses}

Data were fed to the computer and analyzed using IBM SPSS software package version 20.0. (Armonk, NY: IBM Corp). Qualitative data e.g. gender of patients was described using number and percent. The Kolmogorov-Smirnov test was used to verify the normality of distribution. Quantitative data e.g. age of patients was described using median and range (minimum and maximum) or mean and standard deviation. Significance of the obtained results was judged at the $5 \%$ level. The used tests were; Chi-square test to compare between different groups with categorical variables, Fisher's Exact or Monte Carlo correction for chi-square when more than $20 \%$ of the cells have expected count less than 5, Kappa test for agreement testing. Receiver 
operating characteristic (ROC) curve was generated by plotting sensitivity (true positive) on $\mathrm{Y}$ axis versus 1-specificity (false positive) on $\mathrm{X}$ axis at different cutoff values. The area under the ROC curve (AUC) denotes the diagnostic performance of the test. Area more than $50 \%$ gives acceptable performance and area about $100 \%$ is the best performance for the test. The ROC curve allows comparison of performance between two tests.

\section{Ethical considerations}

The study was approved by the Institutional Human Research Ethics Committee of the Faculty of Medicine - Alexandria University (Approval \#: 020870) and a written informed consent was obtained from all participants before enrolment in the study. Patients were all coded and detailed information was stored confidentially.

\section{Results}

Among the 80 included patients, 34 (42.5\%) were males and 46 (57.5\%) females and their age ranged from 41 to 70 years with a mean of 57.1 years.

Forty-six (57.5\%) patients had stage II rectal cancer, while 34 (42.5\%) had stage III. Pathologically, 18 (22.5\%) had well differentiated adenocarcinoma, 48 (60\%) had moderately differentiated adenocarcinoma, while 14 (17.5\%) had mucinous carcinoma. The distance between rectal cancer and anal verge was $\leq 5 \mathrm{~cm}$ in 26 (32.5\%) patients and $>5 \mathrm{~cm}$ in $54(67.5 \%)$ patients. The pretreatment level of CEA was $\leq 5 \mathrm{ng} / \mathrm{ml}$ in 36 (45\%) patients and $>5 \mathrm{ng} / \mathrm{ml}$ in 44 (55\%) patients.

Fifty (62.5\%) patients had hypomethylated while 30 (37.5 \%) had hypermethylated TFAP2E gene promotor. Thirty-six (45 \%) patients had hypomethylated while $44 \quad(55 \%)$ had hypermethylated MLH1 gene promotor. The cutoff values for TFAP2E \& MLH1 genes 'methylation level (to distinguish between hypermethylated and hypomethylated genes) were $40 \%$ and $15 \%$ by ROC curve (AUC $=0.749$ and 0.799 respectively, Figure 3 ).

Fifty-eight (72.5\%) patients were MSS and 22 (27.5\%) patients were MSI.

Assessment of response to nCRT by pathological TRG and radiological RECIST criteria were in good agreement with each other by kappa test $(0.751$ with $\mathrm{p}<0.001)$. Pathological response is more sensitive to changes at cellular level. The relation between clinico-pathological data and pathological response to nCRT are summarized in Table 1 . Factors associated with significantly higher pathological response to nCRT were well / moderately differentiated adenocarcinomas, pretreatment level of CEA $\leq 5 \mathrm{ng} / \mathrm{ml}$, rectal tumors $\leq 5 \mathrm{~cm}$ from the anal verge, microsatellite stability, hypomethylated TFAP2E gene and hypomethylated MLH1 gene.

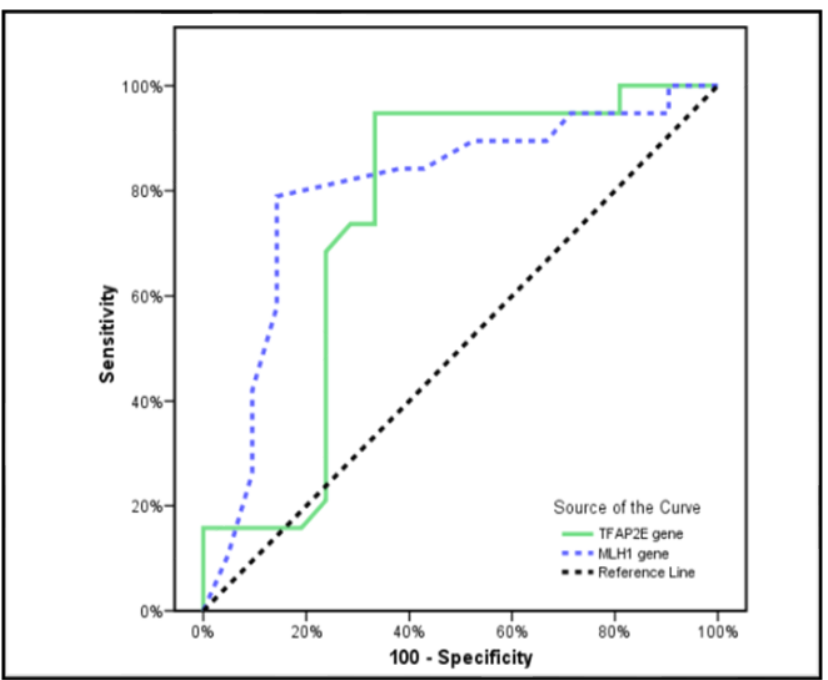

\section{Figure 3: ROC curve analysis of methylation \% values for TFAP2E and MLH1 genes}

There was no statistically significant association between methylation level of the TFAP2E gene promotor and age, gender, TNM stage and histological type (Table 2). Similarly, there was no statistically significant association between these variables and the methylation level of the MLH1 gene promotor (Table 2 ).

Hypomethylated MLH1 gene $(\leq 15 \%)$ was significantly associated with MSS of rectal tumors $(p=0.011)$. There were significant associations between gender of patients, histological type and microsatellite status of rectal tumors with predominance of MSI among females and those having mucinous carcinoma (Table 2).

\section{Discussion}

Hypermethylated TFAP2E and MLH1 gene promotors were found to be predominant among rectal cancer patients who did not respond to nCRT, while hypomethylated genes were predominant among responders. We did not find statistically significant associations between methylation levels of both TFAP2E and MLH1 genes and clinico- 
pathological characteristics of patients (age, gender, histological tumor type and TNM stage).

In agreement with our study, Ebert et al ${ }^{10}$ stated that the probability of response to 5- FU-based nCRT was six times higher among rectal cancer with TFAP2E gene hypomethylation ( $\leq 30 \%$ methylation level) than among rectal cancer with TFAP2E gene hypermethylation ( $>30 \%$ methylation level). Also, they reported that there was insignificant association between methylation level of TFAP2E gene and gender, histological type and TNM stage of rectal cancer. Murcia et al ${ }^{28}$ conducted their study on 783 patients with stages II-IV CRC who received
5-FU-based CRT; 532 patients from a populationbased multicenter cohort and 251 patients from a clinic-based trial. They aimed at evaluating the effectiveness of TFAP2E methylation and expression as a predictor of response of CRC patients to 5-FU-based CRT. The methylation status of TFAP2E gene was assessed by quantitative bisulfite pyrosequencing technique using PSQ HS 96A pyrosequencing system (QIAGEN). Optimal methylation cutoff was calculated by ROC curve analysis and was $40 \%$ with an AUC of 0.73 . In contrast to our results, they reported that TFAP2E gene methylation level, either hypermethylated

Table 1: Relation between clinico-pathological data and pathological response of rectal cancer to neoadjuvant chemoradiotherapy

\begin{tabular}{|c|c|c|c|}
\hline & $\begin{array}{l}\text { Responders } \\
(n=38)\end{array}$ & $\begin{array}{l}\text { Non-responders } \\
(n=42)\end{array}$ & $P$-value \\
\hline & $n(\%)$ & $n(\%)$ & \\
\hline \multicolumn{4}{|l|}{ Age (years) } \\
\hline$\leq 50$ & $8(21.1)$ & $14(33.3)$ & \multirow[t]{2}{*}{$0.385^{*}$} \\
\hline$>50$ & $30(78.9)$ & $28(66.7)$ & \\
\hline \multicolumn{4}{|l|}{ Gender } \\
\hline Male & $18(47.4)$ & $16(38.1)$ & \multirow[t]{2}{*}{$0.554^{*}$} \\
\hline Female & $20(52.6)$ & $26(61.9)$ & \\
\hline \multicolumn{4}{|l|}{ Stage } \\
\hline II & $18(47.4)$ & $28(66.7)$ & \multirow[t]{2}{*}{$0.218^{*}$} \\
\hline III & $20(52.6)$ & $14(33.3)$ & \\
\hline \multicolumn{4}{|l|}{ Histological type } \\
\hline Well differentiated adenocarcinoma & $12(31.6)$ & $6(14.3)$ & \multirow[t]{2}{*}{$0.015^{* *}$} \\
\hline Moderately differentiated adenocarcinoma & $26(68.4)$ & $22(52.4)$ & \\
\hline Mucinous carcinoma & 0 & $14(33.3)$ & \\
\hline \multicolumn{4}{|l|}{ Pre-treatment CEA level (ng/ml) } \\
\hline$\leq 5$ & $26(68.4)$ & $10(23.8)$ & \multirow[t]{2}{*}{$0.005^{*}$} \\
\hline$>5$ & $12(31.6)$ & $32(76.2)$ & \\
\hline \multicolumn{4}{|l|}{ Distance from anal verge $(\mathrm{cm})$} \\
\hline$\leq 5$ & $20(52.6)$ & $6(14.3)$ & \multirow[t]{2}{*}{$0.010^{*}$} \\
\hline$>5$ & $18(47.4)$ & $36(85.7)$ & \\
\hline \multicolumn{4}{|l|}{ TFAP2E gene methylation (\%) } \\
\hline$\leq 40$ (hypomethylation) & $36(94.7)$ & $14(33.3)$ & \multirow[t]{2}{*}{$<0.001^{*}$} \\
\hline$>40$ (hypermethylation) & $2(5.3)$ & $28(66.7)$ & \\
\hline \multicolumn{4}{|l|}{ MLH1 gene methylation (\%) } \\
\hline$\leq 15$ (hypomethylation) & $30(78.9)$ & $6(14.3)$ & \multirow[t]{2}{*}{$<0.001^{*}$} \\
\hline >15 (hypermethylation) & $8(21.1)$ & $36(85.7)$ & \\
\hline \multicolumn{4}{|l|}{ Microsatellite status } \\
\hline Stable (MSS and MSI-L) & $34(89.5)$ & $24(57.1)$ & \multirow[t]{2}{*}{$0.022^{*}$} \\
\hline Instable (MSI-H) & $4(10.5)$ & $18(42.9)$ & \\
\hline
\end{tabular}

CEA: Carcinoembryonic antigen; MSS: Microsatellite stability, MSI-L: Microsatellite instability- low, MSI-H: Microsatellite instability- high; *Pearson's chi-squared test, ${ }^{* *}$ Monte Carlo test 
Table 2: Relation between clinico-pathological data and promotor methylation of TFAP2E and MLH1 genes and Microsatellite Status

\begin{tabular}{|c|c|c|c|c|c|c|c|c|c|}
\hline & \multicolumn{3}{|c|}{$\begin{array}{l}\text { TFAP2E gene promotor } \\
\text { methylation level }\end{array}$} & \multicolumn{3}{|c|}{$\begin{array}{l}\text { MLH1 gene promotor } \\
\text { methylation level }\end{array}$} & \multicolumn{3}{|c|}{$\begin{array}{l}\text { Microsatellite } \\
\text { Status }\end{array}$} \\
\hline & $\begin{array}{l}\leq 40 \\
(n=50)\end{array}$ & $\begin{array}{l}>40 \\
(n=30)\end{array}$ & $\begin{array}{l}P \text { - } \\
\text { value }\end{array}$ & $\begin{array}{l}\leq 15 \% \\
(n=36)\end{array}$ & $\begin{array}{l}>15 \% \\
(n=44)\end{array}$ & $\begin{array}{l}\mathrm{P}- \\
\text { value }\end{array}$ & $\begin{array}{l}\text { Stable } \\
(\mathrm{n}=58)\end{array}$ & $\begin{array}{l}\text { Instable } \\
(\mathrm{n}=22)\end{array}$ & $\begin{array}{l}\mathrm{P}- \\
\text { value }\end{array}$ \\
\hline & n (\%) & n (\%) & & n (\%) & n (\%) & & n (\%) & n (\%) & \\
\hline \multicolumn{10}{|l|}{ Age (years) } \\
\hline$\leq 50$ & $14(28)$ & $8(26.7)$ & $1^{*}$ & $6(16.7)$ & $16(36.4)$ & $0.286^{*}$ & $16(27.6)$ & $6(27.3)$ & $1^{*}$ \\
\hline$>50$ & $36(72)$ & $22(73.3)$ & & $30(83.3)$ & $28(63.6)$ & & $42(72.4)$ & $16(72.7)$ & \\
\hline \multicolumn{10}{|l|}{ Gender } \\
\hline Male & $22(44)$ & $12(40)$ & $0.804^{*}$ & $18(50)$ & $16(36.4)$ & $0.385^{*}$ & $32(55.2)$ & $2(9.1)$ & $0.012^{*}$ \\
\hline Female & $28(56)$ & $18(60)$ & & $18(50)$ & $28(63.6)$ & & $26(44.8)$ & $20(90.9)$ & \\
\hline \multicolumn{10}{|l|}{ Stage } \\
\hline$\underline{\text { II }}$ & $24(48)$ & $22(73.3)$ & 0.117 & $18(50)$ & $28(63.6)$ & $0.385^{*}$ & $30(51.7)$ & $16(72.7)$ & $0.297 *$ \\
\hline III & $26(52)$ & $8(26.7)$ & & $18(50)$ & $16(36.4)$ & & $28(48.3)$ & $6(27.3)$ & \\
\hline \multicolumn{10}{|l|}{ Histological type } \\
\hline $\begin{array}{l}\text { Well differentiated } \\
\text { adenocarcinoma }\end{array}$ & $16(32)$ & $2(6.7)$ & $0.061^{* *}$ & $10(27.8)$ & $8(18.2)$ & $0.222^{* *}$ & $16(27.6)$ & $2(9.1)$ & $0.018^{* *}$ \\
\hline $\begin{array}{l}\text { Moderately } \\
\text { differentiated } \\
\text { adenocarcinoma }\end{array}$ & $30(60)$ & $18(60)$ & & $24(66.7)$ & $24(54.5)$ & & $38(65.5)$ & $10(45.5)$ & \\
\hline Mucinous carcinoma & $4(8)$ & $10(33.3)$ & & $2(5.6)$ & $12(27.3)$ & & $4(6.9)$ & $10(45.5)$ & \\
\hline \multicolumn{10}{|l|}{$\begin{array}{l}\text { MLH1 gene promotor } \\
\text { methylation level }\end{array}$} \\
\hline$\leq 15$ & --- & --- & --- & --- & --- & --- & $34(58.6)$ & $2(9.1)$ & $0.011^{*}$ \\
\hline$>15$ & -- & -- & & -- & --- & & $24(41.4)$ & $20(90.9)$ & \\
\hline
\end{tabular}

*Fisher's Exact test, **Monte Carlo test

$(>40 \%)$ or hypomethylated $(\leq 40 \%)$, did not significantly play a major role in predicting response to 5FU-based CRT in rectal cancer patients $(\mathrm{p}=0.2)$. This dissimilarity in results may be due to differences in ethnic groups, larger sample size (783 vs 80 ) and selection criteria of patients (stages II-IV vs stages II and III CRC). However, in agreement with our study, they reported that none of the clinico-pathological characteristics of patients enrolled in their study was significantly associated with TFAP2E gene methylation level.

We found that hypermethylated MLH1 gene was significantly associated with MSI of rectal tumors. However, none of the clinico-pathological data such as age, gender, histological type and TNM stage of the tumor was significantly related to MLH1 gene methylation level.

Arnold et al ${ }^{29}$ also reported that hyper methylation of MLH1 gene is significantly associated with the MSI phenotype in CRC. Also, Moreira et al ${ }^{30}$ reported similar results. They found that MLH1 gene hypermethylation (>15\%) was prevalent in MSI tumors and MLH1 gene hypomethylation $(<15 \%)$ was present in MSS tumors. They also reported that some of the clinicopathological data, including age, gender and histological type of the tumor were not significantly related to MLH1 gene methylation status.

In our study, we found that MSS rectal tumors had a good response to 5-FU-based nCRT, while MSI tumors had lower response. MSI rectal tumors were predominant among female patients and patients with mucinous carcinoma with no statistically significant relation to either patients' age or rectal tumor stage.

Yang et al ${ }^{15}$ conducted their study on patients with stage II rectal adenocarcinoma who received adjuvant therapy. In agreement with our study, they reported that 5-FU-based CRT had more benefits in MSS rectal cancer, but not with MSI. These results were supported by those of Sargent et al ${ }^{14}$ and Ribic et al ${ }^{31}$. Ribic et al ${ }^{31}$ reported that 
some of the clinico-pathological variables including age and tumor stage were not significantly related to microsatellite status of the tumor, in contrast with the poorly differentiated histological type of the tumor that was reported to be significantly related to its MSI.

In contrast to our study, Thomas et al ${ }^{32}$ reported that the benefit from 5-FU-based CRT in patients with rectal cancer was not significantly related to microsatellite status of the tumor, whether stable or not, and that the beneficial effect of 5-FU-based CRT was found in both MSI and MSS tumors. This dissimilarity in results may be due to ethnicityrelated factors, difference in sample size (814 vs 80) and selection criteria of patients (stage C CRC, according to Australian Clinico-pathological Staging System, who received 5-FU-based chemotherapy vs stages II and III rectal cancer receiving nCRT). However, in agreement with our results, they reported that some of the clinico-pathological data enrolled in their study including female gender and poorly differentiated histological type of the tumor were significantly related to MSI of the tumor.

Among the strengths of the current study are the multiple clinical and laboratory factors studied to predict the response of rectal cancer patients to nCRT and the strict exclusion and inclusion criteria adopted for the selection of cases to avoid confounding factors that could affect the results as much as possible. Another strength is that the response to nCRT was assessed both pathologically and radiologically. The main limitation was the relatively small sample size due to limited budget.

To the best of our knowledge, this is the first study conducted on Egyptian patients with rectal cancer aiming at determining the role of some clinical and laboratory markers; TFAP2E and MLH1 genes and MSI in predicting their response to 5-FUbased nCRT.

\section{Conclusion}

Hypermethylation of TFAP2E and MLH1 gene promotors and MSI of rectal cancer are associated with a lower response rate to 5-FU-based CRT, indicating that they are potential predictors of treatment response in patients with rectal cancer who might benefit in the future from demethylating agents.

\section{Acknowledgement}

None.

Authors' contribution
Conception or design: MMR and EZE; Acquisition, analysis or interpretation of data: WGE, AEK, SMH, DNY and EZE; Drafting the manuscript: EZE; Revising the manuscript: DNY; Final approval of the manuscript version to be published: All authors; Agreement to be accountable for all aspects of the work: All authors.

\section{Conflict of interest}

The authors declare that they have no conflict of interest to disclose.

\section{Data a vailability}

Deidentified individual participant data used to produce the results of this study are available from the corresponding author (DNY) upon request.

\section{Funding}

The authors did not receive funding for this study.

\section{Study registration}

None.

\section{References}

1. Torre LA, Siegel RL, Ward EM, Jemal A. Global cancer incidence and mortality rates and trends-an update. Cancer Epidemiol Biomarkers Prev. 2016; 25(1): 16-27.

2. PelvEx Collaborative. Factors affecting outcomes following pelvic exenteration for locally recurrent rectal cancer. Br J Surg. 2018; 105(6): 650-657.

3. National Comprehensive Cancer Network. Rectal $\begin{array}{llll}\text { Cancer (Version 2020). } & \end{array}$ https://www.nccn.org/professionals/physician gls/pdf/ rectal.pdf. Accessed: 18-September-2020.

4. Montroni I, Ugolini G, Saur NM, et al. Personalized management of elderly patients with rectal cancer: expert recommendations of the European Society of Surgical Oncology, European Society of Coloproctology, International Society of Geriatric Oncology, and American College of Surgeons Commission on Cancer. Eur J Surg Oncol. 2018; 44(11): 1685-1702.

5. Madbouly KM, Hussein AM. Changing operative strategy from abdominoperineal resection to sphincter preservation in T3 low rectal cancer after down-staging by neoadjuvant chemo-radiation: a preliminary report. World J Surg. 2015; 39(5): 12481256.

6. Damin DC, Lazzaron AR. Evolving treatment strategies for colorectal cancer: a critical review of current therapeutic options. World J Gastroenterol. 2014; 20(4): 877-887.

7. Dossa F, Acuna SA, Rickles AS, et al. Association between adjuvant chemotherapy and overall survival in patients with rectal cancer and pathological complete response after neoadjuvant chemotherapy and resection. JAMA Oncol. 2018; 4(7): 930-937.

8. García-Flórez LJ, Gómez-Álvarez G, Frunza AM, Barneo-Serra L, Martínez-Alonso C, Fresno-Forcelledo MF. Predictive markers of response to neoadjuvant 
therapy in rectal cancer. J Surg Res. 2015; 194(1): 120 126.

9. Williamson JS, Harris DA, Beynon J, Jenkins GJS Review of the development of DNA methylation as a marker of response to neoadjuvant therapy and outcomes in rectal cancer. Clin Epigenetics. 2015; 7(1): 70 .

10. Ebert MP, Tänzer M, Balluff B, et al. TFAP2E-DKK4 and chemo-resistance in colorectal cancer. N Engl J Med. 2012; 366(1): 44-53.

11. Beggs AD, Dilworth MP, Domingo E, et al. Methylation changes in the TFAP2E promoter region are associated with BRAF mutation and poorer overall \& disease free survival in colorectal cancer. Oncoscience. 2015; 2(5): 508-516.

12. Grandval P, Fabre AJ, Gaildrat P, et al. UMDMLH1/MSH2/MSH6 databases: description and analysis of genetic variations in French Lynch syndrome families. Database (Oxford). 2013; 2013: bat036.

13. Boland CR, Goel A. Microsatellite instability in colorectal cancer. Gastroenterology. 2010; 138(6): 2073-2087.e3.

14. Sargent DJ, Marsoni S, Monges G, et al. Defective mismatch repair as a predictive marker for lack of efficacy of fluorouracil-based adjuvant therapy in colon cancer. J Clin Oncol. 2010; 28(20): 3219-3226.

15. Yang L, Sun Y, Huang XE, et al. Carcinoma microsatellite instability status as a predictor of benefit from fluorouracil-based adjuvant chemotherapy for stage II rectal cancer. Asian Pac J Cancer Prev. 2015; 16(4): 1545-1551.

16. Hofstetter B, Niemierko A, Forrer C, et al. Impact of genomic methylation on radiation sensitivity of colorectal carcinoma. Int J Radiat Oncol Biol Phys. 2010; 76(5): 1512-1519.

17. Exner R, Pulverer W, Diem M, et al. Potential of DNA methylation in rectal cancer as diagnostic and prognostic biomarkers. Br J Cancer. 2015; 113(7): 1035-1045.

18. Dahlin AM, Palmqvist R, Henriksson ML, et al. The role of the $\mathrm{CpG}$ island methylator phenotype in colorectal cancer prognosis depends on microsatellite instability screening status. Clin Cancer Res. 2010; 16(6): 1845-1855.

19. Park J, Lee S, Kim Y, et al. Comparison of four automated carcinoembryonic antigen immunoassays: ADVIA Centaur XP, ARCHITECT I2000sr, Elecsys E170, and Unicel Dxi800. Ann Lab Med. 2018; 38(4): 355-361.

20. Groelz D, Viertler C, Pabst D, Dettmann N, Zatloukal K. Impact of storage conditions on the quality of nucleic acids in paraffin embedded tissues. PloS One. 2018; 13(9): e0203608.
21. Holmes EE, Jung M, Meller S, et al. Performance evaluation of kits for bisulfite-conversion of DNA from tissues, cell lines, FFPE tissues, aspirates, lavages, effusions, plasma, serum, and urine. PloS One. 2014; 9(4): e93933.

22. Fusco G, Amoroso MG, Montesano NG, Viscardi M. Development of a pyrosequencing assay for the typing of alphaherpesviruses. MethodsX. 2015 ;2: 47-52.

23. Dean DA, Wadl PA, Hadziabdic D, Wang X, Trigiano RN. Analyzing microsatellites using the QIAxcel system. Methods Mol Biol. 2013; 1006: 223-243.

24. Förster I, Brockmann M, Schildgen O, Schildgen V. Microsatellite instability testing in colorectal cancer using the QiaXcel advanced platform. BMC Cancer. 2018; 18(1): 484.

25. Cisyk AL, Nugent Z, Wightman RH, Singh H, McManus KJ. Characterizing microsatellite instability and chromosome instability in interval colorectal cancers. Neoplasia. 2018; 20(9): 943-950.

26. Akinwande O, Philips $P$, Scoggins $C R$, et al. Comparison of tumor response assessment methods in patients with metastatic colorectal cancer after locoregional therapy. J Surg Oncol. 2016; 113(4): 443448.

27. Mancini R, Pattaro G, Diodoro MG, et al. Tumor regression grade after neoadjuvant chemoradiation and surgery for low rectal cancer evaluated by multiple correspondence analysis: Ten years as minimum follow-up. Clin Colorectal Cancer. 2018; 17(1): e13-e19.

28. Murcia O, Jover R, Egoavil C, et al. TFAP2E methylation and expression status does not predict response to 5-FU-based chemotherapy in colorectal cancer. Clin Cancer Res. 2018; 24(12): 2820-2827.

29. Arnold CN, Goel A, Compton C, et al. Evaluation of microsatellite instability, hMLH1 expression and hMLH1 promoter hypermethylation in defining the MSI phenotype of colorectal cancer. Cancer Biol Ther. 2004; 3(1): 73-78.

30. Moreira L, Munoz J, Cuatrecasas M, et al. Prevalence of somatic mutl homolog 1 promoter hypermethylation in Lynch syndrome colorectal cancer. Cancer. 2015; 121(9): 1395-1404.

31. Ribic CM, Sargent DJ, Moore MJ, et al. Tumor microsatellite-instability status as a predictor of benefit from fluorouracil-based adjuvant chemotherapy for colon cancer. N Engl J Med. 2003 ;349(3): 247-257.

32. Thomas ML, Hewett PJ, Ruszkiewicz AR, Moore JWE. Clinico-pathological predictors of benefit from adjuvant chemotherapy for stage $C$ colorectal cancer: Microsatellite unstable cases benefit. Asia Pac J Clin Oncol. 2015; 11(4): 343-351. 